\title{
Oral protein energy supplements for children with cystic fibrosis: CALICO multicentre randomised controlled trial
}

Vanessa J Poustie, Jayne E Russell, Ruth M Watling, Deborah Ashby, Rosalind L Smyth, on behalf of the CALICO

Trial Collaborative Group

\begin{abstract}
Objective To determine whether oral protein energy supplements, used long term in children with cystic fibrosis who are moderately malnourished, improve nutritional and other outcomes.

Design Multicentre randomised controlled trial.

Setting Seven specialist paediatric cystic fibrosis centres and their associated shared care clinics and seven smaller paediatric cystic fibrosis clinics.

Participants 102 children with cystic fibrosis, aged between 2 and 15 years, who were moderately malnourished.

Interventions Oral protein energy supplements in addition to usual dietary advice compared with dietary advice alone, for 12 months.
\end{abstract}

Main outcome measure Change in body mass index centile over one year.

Results Use of supplements was not associated with a change in body mass index centile (mean difference 2.99 centile points, $95 \%$ confidence interval -2.70 to 8.68 ) or other nutritional and spirometric outcomes in this group of children.

Conclusions Long term use of oral protein energy supplements did not result in an improvement in nutritional status or other clinical outcomes in children with cystic fibrosis who were moderately malnourished. Oral protein energy supplements should not be regarded as an essential part of the management of this group of children.

Trial registration ISRCTN: 95744468.

\section{Introduction}

Poor nutrition is common in people with cystic fibrosis-a large study in the United States reported that $50 \%$ were under the 10th centile for height, weight, or both. ${ }^{1}$ Prevalence of poor nutritional status increases with age and is an important predictor of decline in lung function..$^{2-5}$ In recent years several guidelines have recommended that dietary intake should provide at least $120 \%$ of the recommended daily allowance for energy in people with cystic fibrosis. ${ }^{6-8}$ Achieving this energy intake from food can be difficult and is usually not successful, particularly in young children. ${ }^{9} 10$

Oral protein energy supplements are widely prescribed for people with cystic fibrosis to improve energy intake and nutritional status. ${ }^{8}$ They are used in the medium to long term when weight gain is not satisfactory or in the short term to enable weight that has been lost acutely to be regained. They are considered an acceptable, non-invasive means of improving nutritional status and overall prognosis in children who have increased energy requirements. ${ }^{11}$ However, many people find them unpalatable, particularly when prescribed for long term use.

These supplements are expensive and have never been evaluated in a large randomised controlled trial in children. ${ }^{12} \mathrm{~A}$ systematic review of oral protein energy supplements for people with cystic fibrosis identified two eligible trials, which together involved 29 participants. ${ }^{13}$ Because of a lack of evidence, the review was unable to reach a conclusion on the efficacy of these supplements (fig 1). The aim of the CALICO (calories in cystic fibrosis-oral) trial was to investigate whether oral protein energy supplements, taken as drinks, in addition to dietary advice and monitoring, improve or prevent deterioration in the body mass index centile of children with cystic fibrosis compared with dietary management alone. The trial also evaluated the effect of supplements on other measures of nutritional status, macronutrient intake, spirometric lung function, activity levels, and gastrointestinal symptoms.

\section{Methods}

\section{Study design}

The trial was a multicentre randomised controlled trial of oral protein energy supplements for children with cystic fibrosis. We first did a feasibility study to refine the methods, determine which outcome measures to use, and allow consumers and collaborators to be involved in the development of the CALICO trial. $^{14}$

\section{Participants}

We recruited children with cystic fibrosis aged between 2 and 15 years if they met one of the following criteria: body mass index of less than the 25th centile and more than the 0.4th centile, no increase in weight over the previous three months, a $5 \%$ decrease in weight from baseline over a period of less than six months. We excluded children who had cystic fibrosis related diabetes or liver disease or had a forced expiratory volume in one second of less than $30 \%$ of predicted for height and age or if, during the previous three months, they had been diagnosed as having cystic fibrosis or had received enteral nutrition. Children who were excluded were considered eligible later if these criteria no longer applied. Children were recruited by dietitians at seven specialist cystic fibrosis centres in the United Kingdom, and associated shared care clinics, and at seven smaller clinics. The parents of all

Members of Trial Steering Committee and the Collaborative Group are on bmj.com 
Table 1 Oral protein energy supplements prescribed to children in the supplement group

\begin{tabular}{llc} 
Supplement & Manufacturer & $\begin{array}{c}\text { No prescribed this } \\
\text { product }\end{array}$ \\
\hline Calshake & Fresenius Kabi, Runcorn & 6 \\
\hline Clinutren & Nestle UK, Croydon & 7 \\
\hline Complan & Heinz, Hayes & 2 \\
\hline Enlive & Fresenius Kabi, Runcorn & 7 \\
\hline Fortifresh & Nutricia Clinical Nutrition, Croydon & 1 \\
\hline Fortijuice & Nutricia Clinical Nutrition, Croydon & 7 \\
\hline Fortini & Nutricia Clinical Nutrition, Croydon & 1 \\
\hline Fortisip & Nutricia Clinical Nutrition, Croydon & 4 \\
\hline Fresubin & Fresenius Kabi, Runcorn & 5 \\
\hline Resource & Novartis Consumer Health, Horsham & 5 \\
\hline Scandishake & SHS International, Liverpool & 5 \\
\hline
\end{tabular}

participating children gave informed written consent, in addition to the children's own signed assent where appropriate.

\section{Interventions}

We provided the children with a selection of supplements to try before randomisation. We randomised those who found the supplements palatable to receive either oral protein energy supplements plus routine dietetic advice (supplement group) or routine dietetic advice excluding prescription of such supplements (standard care group) for one year. We did not randomise children who did not find the supplements palatable. The children selected the supplements that they liked, and we recommended a daily amount sufficient to increase usual energy intake by $20 \%$ (table 1). We excluded supplements that provided only energy or protein alone. We asked the child's general practitioner to prescribe the supplements. A research assistant (JER) made five home visits to each child, one to explain the trial and sample the supplements and four to assess all outcomes at baseline and at three, six, and 12 months.

\section{Outcomes}

The primary outcome was change in body mass index centile over 12 months. We measured weight by using portable scales (Seca, Birmingham, UK) and height by using the Leicester Height Measure, a freestanding stadiometer (Seca). We assessed tricep skinfold thickness with Holtain skinfold callipers (Holtain, Crymych, UK) and mid-upper arm circumference, which we used to calculate mid-arm muscle circumference ${ }^{15}$ We calculated energy and macronutrient intake from four day, unweighed diet diaries by using the Microdiet software (Downlee Systems, Chapel-en-le Frith, UK) and expressed these as a percentage of the recommended daily intake for age and sex. ${ }^{16}$ We measured spirometric lung function parameters (forced expiratory volume in one second and forced vital capacity) with a portable spirometer (Vitalograph, Buckingham, UK) and expressed them as a percentage of that predicted for age, sex, and height. We used the habitual activity estimation scale to assess activity levels expressed as a percentage of 24 hours spent being active. ${ }^{17}$ We monitored gastrointestinal symptoms with a questionnaire adapted from a validated tool. ${ }^{18}$ The research assistant was trained in anthropometric assessment and spirometry and used regularly calibrated equipment.

\section{Randomisation}

We used random number tables to generate the randomisation code. Sequentially numbered, opaque envelopes, administered by the pharmacy of the lead centre, were used for treatment group allocation. Randomisation was stratified within each centre. The research assistant was not masked to allocation group, but a masked investigator (VJP) used a computerised growth package for conversion of weight and height to body mass index centile. ${ }^{19}$ The children in the trial were not masked, as we had no satisfactory placebo. On two occasions twins were randomised, both siblings at the same time. In each instance, both twins were randomised to the same group. A further pair of siblings were entered into the trial at different times and were randomised separately. We took no formal account of this in the modelling.

\section{Statistical analysis}

We set the study size to detect a difference of a change of 10 body mass index centiles between the two groups after one year. This estimation was based on data from two cystic fibrosis centres. With a 5\% significance level and 90\% power, using a conservatively estimated standard deviation for one year change in body mass index centile of 15 points, we needed 47 children in each arm or 94 in total. Statistical analysis was by intention to treat, which we did according to a pre-established analysis plan with the analyst masked to treatment allocation. We calculated differences in mean change in body mass index centile and all other outcomes over 12 months between the supplement and standard care groups, with 95\% confidence intervals for the difference. We used Student's $t$ test to calculate P values. We made

Review: Oral calorie supplements for cystic fibrosis

Comparison: 01 Oral supplements versus no intervention or additional nutritional advice

Outcome: 01 Change in weight in $\mathrm{kg}$

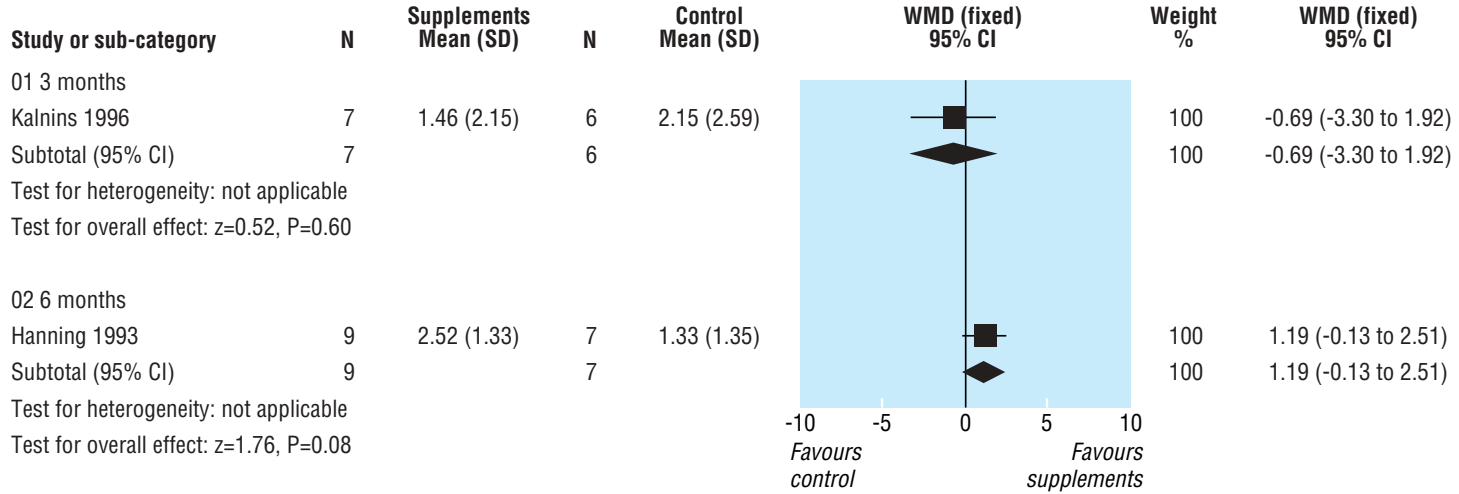

Fig 1 Forrest plot showing effect of oral protein energy supplements, compared with no intervention or additional nutritional advice, on change in weight (taken from Cochrane systematic review of oral calorie supplements for cystic fibrosis ${ }^{13}$ ) 
Table 2 Baseline characteristics of participants. Values are means (SDs)

\begin{tabular}{lcc} 
Characteristic & $\begin{array}{c}\text { Supplement group }(\mathbf{n}=\mathbf{5 0 , 2 7} \\
\text { boys) }\end{array}$ & $\begin{array}{c}\text { Standard care group ( } \mathbf{n}=\mathbf{5 2 , 2 7} \\
\text { boys) }\end{array}$ \\
\hline Age (years) & $8.75(3.72)$ & $8.79(3.67)$ \\
\hline BMI centile & $34.27(23.96)$ & $31.52(25.36)$ \\
\hline Weight centile & $25.07(20.37)$ & $24.69(22.79)$ \\
\hline Height centile & $26.69(24.83)$ & $28.15(26.93)$ \\
\hline Energy intake (\% EAR) & $118.43(28.71)$ & $116.24(29.59)$ \\
\hline FEV ${ }_{1}$ (\% predicted) & $81.34(16.16)$ & $73.67(18.58)$ \\
\hline
\end{tabular}

$\mathrm{BMI}=$ body mass index; $\mathrm{EAR}=$ estimated average requirement for age and sex; $\mathrm{FEV}_{1}=$ forced expiratory volume in 1 second.

every effort to obtain full outcome data on all participants, but we replaced any missing data with routinely collected data where appropriate. This was necessary on only two occasions for diet diary data. Children aged 5 and above did spirometry. As oral protein energy supplements are an established treatment with few adverse effects, the trial did not have a data monitoring committee. The trial steering committee received regular independent audits to check progress of the trial and completeness of documentation.

\section{Results}

Twenty seven dietitians from 21 hospitals recruited 132 of 160 eligible children to the trial. We randomised 102 children recruited from 17 hospitals, 50 to the supplement group and 52 to the standard care group. Figure 2 shows the trial profile. Baseline characteristics of the two groups of children were balanced (table 2). The children recruited but not randomised (20 boys, 10 girls) were similar in age (mean age 9.43 (SD 3.75) years) and nutritional status (mean body mass index centile 26.01 (SD 19.85)) to those randomised.

All children were followed up to 12 months, although we were unable to collect interim data on two children from the supplement group (owing to parental choice or illness) and one child from the standard care group (illness). We found no difference in mean change in body mass index centile from baseline to
Table 3 Change in outcomes over 12 months. Values are means (SDs) unless stated otherwise

\begin{tabular}{|c|c|c|c|c|}
\hline Outcome measure & $\begin{array}{l}\text { Supplement } \\
\text { group }\end{array}$ & $\begin{array}{l}\text { Standard care } \\
\text { group }\end{array}$ & $\begin{array}{l}\text { Mean difference } \\
\quad(95 \% \mathrm{CI})\end{array}$ & $\begin{array}{c}P \\
\text { value }\end{array}$ \\
\hline BMI centile & $0.67(18.20)$ & $-2.32(9.63)$ & 2.99 (-2.70 to 8.68$)$ & 0.30 \\
\hline Weight centile & $0.83(10.96)$ & $-1.00(7.14)$ & $1.83(-1.79$ to 5.45$)$ & 0.32 \\
\hline Height centile & $-0.53(6.94)$ & $1.18(5.62)$ & $\begin{array}{c}-0.65 \\
(-3.12 \text { to } 1.83)\end{array}$ & 0.61 \\
\hline $\begin{array}{l}\text { Mid-arm muscle } \\
\text { circumference }\end{array}$ & $0.76(1.37)$ & $0.62(1.00)$ & 0.14 (-0.34 to 0.61$)$ & 0.08 \\
\hline $\mathrm{FEV}_{1}(\%$ predicted $)$ & $-3.41(13.50)$ & $-1.50(14.89)$ & $\begin{array}{c}-1.91 \\
(-8.73 \text { to } 4.93)\end{array}$ & 0.58 \\
\hline FVC (\% predicted) & $0.06(17.82)$ & $-5.21 \quad(20.02)$ & $\begin{array}{c}5.28 \\
\text { (-3.93 to } 14.48)\end{array}$ & 0.26 \\
\hline $\begin{array}{l}\text { Activity (\% of day } \\
\text { active) }\end{array}$ & $-4.97(9.77)$ & $-4.89(10.70)$ & -0.07 (-4.1 to 3.96) & 0.97 \\
\hline Energy intake (\% EAR) & 24.48 (22.87) & $6.63(25.21)$ & $\begin{array}{c}17.85 \\
\text { (5.11 to } 30.58)\end{array}$ & 0.01 \\
\hline $\begin{array}{l}\text { Gastrointestinal } \\
\text { symptom score }\end{array}$ & $-0.42(2.05)$ & $-0.62(2.03)$ & 0.20 (-0.61 to 1.00$)$ & 0.63 \\
\hline
\end{tabular}

BMI=body mass index; EAR=estimated average requirement for age and sex; $\mathrm{FEV}_{1}=$ forced expiratory volume in 1 second; $F V C=$ forced vital capacity.

12 months between the supplement group and the standard care group (mean difference 2.99 (95\% confidence interval -2.70 to 8.68 ) centile points) (table 3 , fig 3 ). The confidence interval excludes the 10 point difference that the trial was powered to detect. No significant differences at these time points existed between the groups for weight and height centiles or for any other anthropometric outcomes.

Nine children failed to return the baseline diet diary, and 39 failed to return the 12 month diet diary. Dietary intake data are therefore based on the 58 children who completed both baseline and 12 month diaries. We found no differences between mean change from baseline to 12 months for dietary intake outcomes, apart from energy intake expressed as a percentage of that recommended for age and sex (mean difference 17.85 (5.11 to 30.58) percentage points), as shown in table 3. Spirometry data were available for 70 of the 72 participants aged 5 and above. We found no significant differences between the groups for any lung

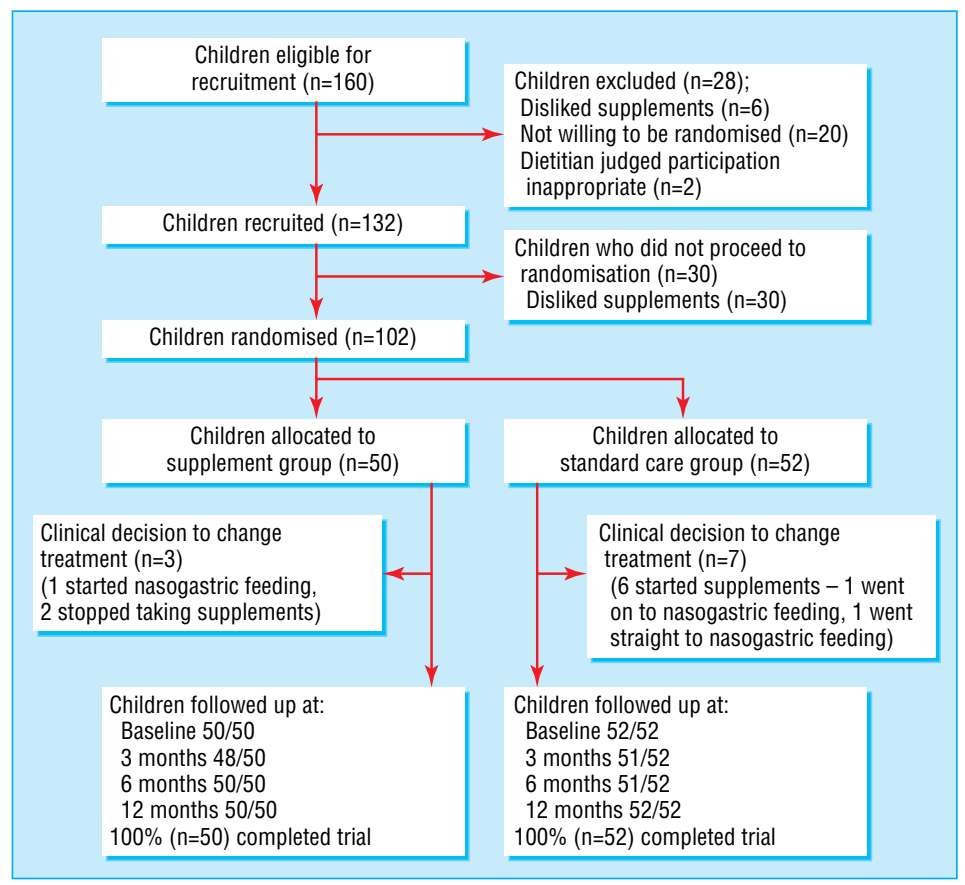

Fig 2 Trial profile 


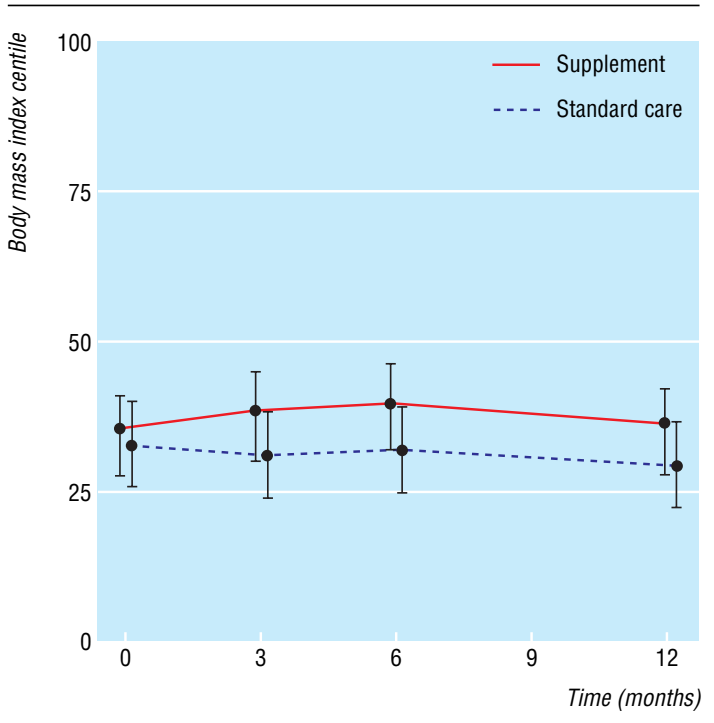

Fig 3 Body mass index centile over one year, by treatment group (lines show means, error bars show $95 \%$ confidence intervals)

function outcomes. All children completed the activity diaries and gastrointestinal symptom questionnaires, and we found no differences between the groups for these outcomes (table 3).

\section{Discussion}

These data suggest that oral protein energy supplements prescribed over one year, compared with dietary advice alone, did not result in a clinically important change in body mass index centile or other nutritional outcomes in children with cystic fibrosis. This pragmatic trial was informed by a systematic review and a pilot study. Addition of our trial data to the systematic review of oral protein energy supplements for people with cystic fibrosis clearly shows the limited efficacy of these products (fig 4).

One of our outcomes related to whether the prescription of oral protein energy supplements improved energy intake, as we were concerned that drinking these products would reduce energy intake from food, thereby not increasing the total intake. A marked improvement in energy intake seemed to occur in the supplement group, compared with the control group, despite the lack of difference in nutritional outcomes. The supplement group seemed to be consuming about $18 \%$ more than the standard care group, relative to their estimated average requirement for energy intake. We made conservative assumptions that, in this group, efficiency of energy storage is $50 \%$ and energy content of new tissue is $6000 \mathrm{kcal} / \mathrm{kg}$ and calculated that, if this difference in energy intake was maintained over one year, the average weight would be $10 \mathrm{~kg}$ greater in the supplement group. The actual mean difference in weight between the groups was $0.17 \mathrm{~kg}(95 \%$ confidence interval -0.68 to $1.02 \mathrm{~kg}$ ), which led us to conclude that the diet diary data are inaccurate. Energy intake data derived from diet diaries are acknowledged to show considerable inaccuracies compared with an objective measure. ${ }^{20}$ Just under half the participants failed to return their diaries, and for those who did it was unclear whether the recording of the number of supplements consumed was accurate. It therefore seems likely that children prescribed supplements overestimated their intake of supplements, food, or both in the diet diaries.

Several studies have investigated the association between nutritional status and lung disease in cystic fibrosis, ${ }^{2}{ }^{3}$ but determining whether poor nutritional status is the cause or an effect of decline in lung function is difficult. However, longitudinal studies in children with cystic fibrosis have shown that weight,

Review: Oral calorie supplements for cystic fibrosis

Comparison: 01 Oral supplements versus no intervention or additional nutritional advice

Outcome: 01 Change in weight in $\mathrm{kg}$

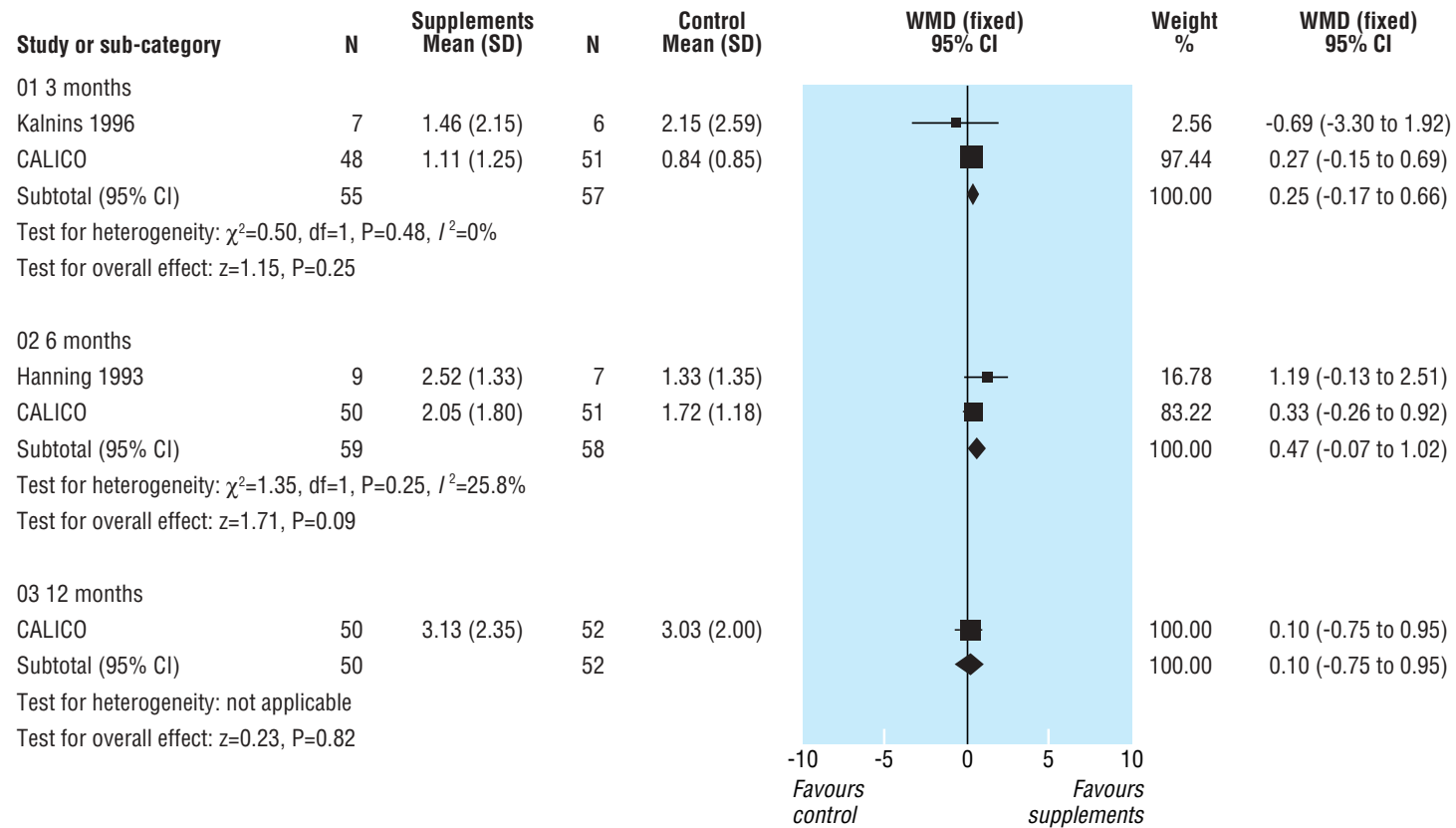

Fig 4 Forrest plot showing effect of oral protein energy supplements, compared with no intervention or additional nutritional advice, on change in weight-adjusted to include evidence from CALICO trial (adapted from Cochrane systematic review of oral calorie supplements for cystic fibrosis ${ }^{13}$ ) 


\section{What is already known on this topic}

Oral protein energy supplements are often prescribed to improve growth and nutritional status in children with cystic fibrosis and other chronic conditions

These supplements are expensive, and many children do not like taking them regularly

Evidence from randomised controlled trials for the effectiveness of supplements is lacking

\section{What this study adds}

Long term use of oral protein energy supplements does not improve nutritional status in children with cystic fibrosis

Dietary advice alone is a satisfactory approach to the management of children with cystic fibrosis and moderate malnutrition

adjusted for age, is an independent predictor of percentage forced expiratory volume in one second some years later. ${ }^{45}$ This study provides important reassurance that children who do not receive supplements, because they either are not prescribed them or do not like them, will not have a decline in nutritional status, with potentially serious long term consequences.

Nutritional supplements are used widely by children with a range of chronic diseases, ${ }^{21}$ for similar indications. That their use has not been evaluated in well designed trials is therefore astonishing. The lack of effectiveness of supplements may be because children do not take them or because they reduce their food intake as a result of taking them. Because of concerns about the inaccuracies in the diet diaries, we have not attempted to assess this further. However, these influences are likely to be similar across different disease groups, and we suggest that trials to assess the effectiveness of nutritional supplements should be done in children with any chronic disease associated with poor nutritional status and growth failure.

\section{Conclusion}

The results of this trial have important implications for the nutritional management of children with cystic fibrosis. We have shown that when children with suboptimal nutrition receive regular dietary advice, their nutritional status is similar whether or not they have supplements. Although oral protein energy supplements may have a place in the treatment of malnourished children, possibly during episodes of acute weight loss, they should not be regarded as an essential part of clinical care.

We thank the children with cystic fibrosis who participated in this trial and their families; Tim Cole, Jim Littlewood, John Reilly, and members of UK CF Dietitians Interest Group for advice on this study; and Larry Lands for allowing us to use the habitual activity estimation scale.

Contributors: All authors read and approved the paper. Every author contributed to the drafting and reviewing of the paper. RLS, VJP, DA, and RMW developed the study protocol. RLS was the lead investigator. VJP was the trial coordinator, analysed the results, and wrote the first draft of the paper. DA was the trial statistician and guided the analysis. RMW was the dietetic adviser and chief recruiter in the lead centre. JER collected all the data and assisted in the analysis. VJP is the guarantor. Gill Lancaster, Centre for
Medical Statistics and Health Evaluation, University of Liverpool, was the auditor and provided the randomisation schedule.

Funding: The trial was funded by a grant from the UK Cystic Fibrosis Trust, which, after initial peer review of the protocol and receipt of regular interim reports, had no further role in the design of the trial, analysis of the results, or reporting of the findings.

Competing interests: VJP, RMW, JER, and several of the dietitians involved in this study have previously received travel expenses to attend conferences from the following manufacturers of oral protein energy supplements: SHS International, Liverpool, UK; Ross Laboratories, IL, USA; Nutricia, Trowbridge, UK; Nestle UK, Croydon.

Ethical approval: Ethical approval was granted by the North West Multi-centre Research Ethics Committee and by the local research ethics committees of all the collaborating centres.

1 FitzSimmons SC. The changing epidemiology of cystic fibrosis.J Pediatr 1993;122:1-9.

2 Steinkamp G, Wiedemann B. Relationship between nutritional status and lung function in cystic fibrosis: cross sectional and longitudinal analyses from the German CF quality assurance (CFQA) project. Thorax 2002;57:596-601.

3 Peterson ML, Jacobs DR Jr, Milla CE. Longitudinal changes in growth parameters are correlated with changes in pulmonary function in children with cystic fibrosis. Pediatrics 2003;112(3 pt 1):588-92.

4 Konstan MW, Butler SM, Wohl ME, Stoddard M, Matousek R, Wagener JS, et al. Growth and nutritional indexes in early life predict pulmonary function in cystic fibrosis. J Pediatr 2003;142:624-30.

5 Zemel BS, Jawad AF, FitzSimmons S, Stallings VA. Longitudinal relationship among growth, nutritional status, and pulmonary function in children with cystic fibrosis: analysis of the Cystic Fibrosis Foundation national CF patient registry. J Pediatr 2000;137:374-80.

6 MacDonald A. Nutritional management of cystic fibrosis. Arch Dis Child 1996;74:81-7. 7 Dodge JA. Nutritional requirements in cystic fibrosis: a review. J Pediatr Gastroenterol Nutr 1988;7(suppl 1):S8-11.

8 Sinaasappel M, Stern M, Littlewood J, Wolfe S, Steinkamp G, Heijerman HG, et al. Nutrition in patients with cystic fibrosis: a European consensus.J Cyst Fibros 2002;1:5175.

9 Kawchak DA, Zhao H, Scanlin TF, Tomezsko JL, Cnaan A, Stallings VA. Longitudinal, prospective analysis of dietary intake in children with cystic fibrosis. I Pediatr prospective analysis
1996; 129:119-29.

10 Powers SW, Patton SR, Byars KC, Mitchell MJ, Jelalian E, Mulvihill MM, et al. Caloric intake and eating behavior in infants and toddlers with cystic fibrosis. Pediatrics 2002;109:E75

11 Dorlochter L, Roksund O, Helgheim V, Rosendahl K, Fluge G. Resting energy expenditure and lung disease in cystic fibrosis. J Cyst Fibros 2002;1:131-6.

12 Poustie VJ, Smyth RL, Watling RM. Oral protein calorie supplementation for children with chronic disease. Cochrane Database Syst Rev 2000;(3):CD001914.

13 Smyth R, Walters S. Oral calorie supplements for cystic fibrosis. Cochrane Database Syst Rev 2000;(2):CD000406.

14 Poustie VJ, Watling RM, Ashby D, Smyth RL. Feasibility study for a randomised controlled trial of oral calorie supplements in children with cystic fibrosis [abstract]. Proceedings of 22nd European Cystic Fibrosis Conference 1998:98.

Proceedings of 22nd European Cystic Fibrosis Conference 1998:98.
15 Manual of dietetic practice. 3rd ed. Oxford: Blackwell Science, 2001.

16 Committee on Medical Aspects of Food Policy. Dietary reference values for food energy and nutrients for the United Kingdom. London: Department of Health, 1991

17 Boucher GP, Lands LC, Hay JA, Hornby L. Activity levels and the relationship to lung function and nutritional status in children with cystic fibrosis. Am J Phys Med Rehabil 1997;76:311-5.

18 Stead RJ, Skypala I, Hodson ME, Batten JC. Enteric coated microspheres of pancreatin in the treatment of cystic fibrosis: comparison with a standard enteric coated preparation. Thorax 1987;42:533-7.

19 Cole TJ, Freeman JV, Preece MA. British 1990 growth reference centiles for weight, height, body mass index and head circumference fitted by maximum penalised likeliheight, body mass index and head
hood. Stat Med 1998;17:407-29.

20 Westerterp KR, Goris AHC. Validity of the assessment of dietary intake: problems of misreporting. Curr Opin Clin Nutr Metab Care 2002;5:489-93.

21 Ball SD, Kertesz D, Moyer-Mileur LJ. Dietary supplement use is prevalent among children with a chronic illness. J Am Diet Assoc 2005;105:78-84. (Accepted 6 January 2006)

doi 10.1136/bmj.38737.600880.AE

University of Liverpool Division of Child Health, Royal Liverpool Children's Hospital, Liverpool L12 2AP

Vanessa J Poustie research associate

Jayne E Russell research assistant

Rosalind L Smyth professor

Department of Nutrition and Dietetics, Royal Liverpool Children's Hospital Ruth M Watling chief dietician

Wolfson Institute of Preventive Medicine, Queen Mary, University of London Deborah Ashby professor of medical statistics

Correspondence to: R L Smyth r.l.smyth@liv.ac.uk 